\title{
Monitoring giant willow aphid (Tuberolachnus salignus) on apple trees in close proximity to infested willows
}

\author{
D.R. Wallis and P.W. Shaw
}

\author{
Plant \& Food Research, Old Mill Road, Motueka 7198, New Zealand \\ Corresponding author: roger.wallis@plantandfood.co.nz
}

The giant willow aphid, was first found in New Zealand in 2013 and is now established throughout the country. An orchardist in the Tasman district reported infestation of his commercial block of young 'Envy' apple trees after harvest in May 2016, adjacent to two large willow trees heavily infested with giant willow aphid. Regular observations commenced soon after to determine seasonal activity, apple tree infestation, timing and impact and any alternative host plants or possible natural enemies. Key observations since are that the giant willow aphids appear in late September on willow shoots near the base of the tree reaching low numbers before disappearing again in late November. At this time, a ladybird species (Adalia bipunctata), where observed in the willows and on other plants nearby. In late December the aphids reappeared on the willows and numbers built to a peak in late February and remained on the willows until leaf fall. The aphids were not seen on the apple trees in any significant numbers until February when infestation and feeding continued until late autumn. After two seasons of infestation, the apple trees closest to the infested willows are now visibly 'sick' with yellowing leaves, stunted growth, reduced fruit production and branches blackened with sooty mould.

\section{Insect pests in stored grain: a Canterbury example}

\author{
J.B. Drummond ${ }^{1}$ J.W.M. Marris ${ }^{2}$ and T. Brooker ${ }^{1}$ \\ ${ }^{1}$ Foundation for Arable Research, PO Box 23133, Templeton, 8445, New Zealand \\ ${ }^{2}$ Bio-Protection Research Centre, PO Box 85084, Lincoln University, 7647, New Zealand \\ Corresponding author: jo.drummond@far.org.nz
}

Grain samples were collected from storage facilities of cereal grain producers throughout Canterbury, New Zealand to determine levels of insect pest infestation. Collection followed a preliminary survey in 2015/16 where growers were invited to submit grain samples. It was possible that producers were more likely to send samples if they suspected insect infestation. To eliminate any survey sampling bias in the 2016/17 survey, 42 cereal grain producers were randomly selected. Fifty-eight grain samples were collected from 42 storage facilities, of which $77 \%$ were infested with one or more insect species. These were predominantly Coleoptera and Psocoptera. The most frequently encountered beetle species were Orzyaephilis surinamensis and Cryptolestes species. In contrast to the 2015/16 survey, a Sitophilus (weevil) species was recorded for the first time. The proportion of storage facilities infested by insects (77\%) was similar to the 2015/16 survey (73\%) but higher than two previous surveys in 1971 (38\%) and 1979 (50-63\%). The proportion of storage facilities treated with insecticides (79\%) was similar to the 1979 survey (83\%) but greater than the preliminary 2015/16 survey (62\%). Results indicate that insect pests of stored grain remain a significant risk for grain producers. 